\title{
The problem of subjectivity of values in the search for a universal environmental ethics
}

\author{
Yuksel Sarac Yesilada ${ }^{*}$ \\ ${ }^{1}$ Faculty of Letters, Department of Philosophy, Karabuk University, Turkey
}

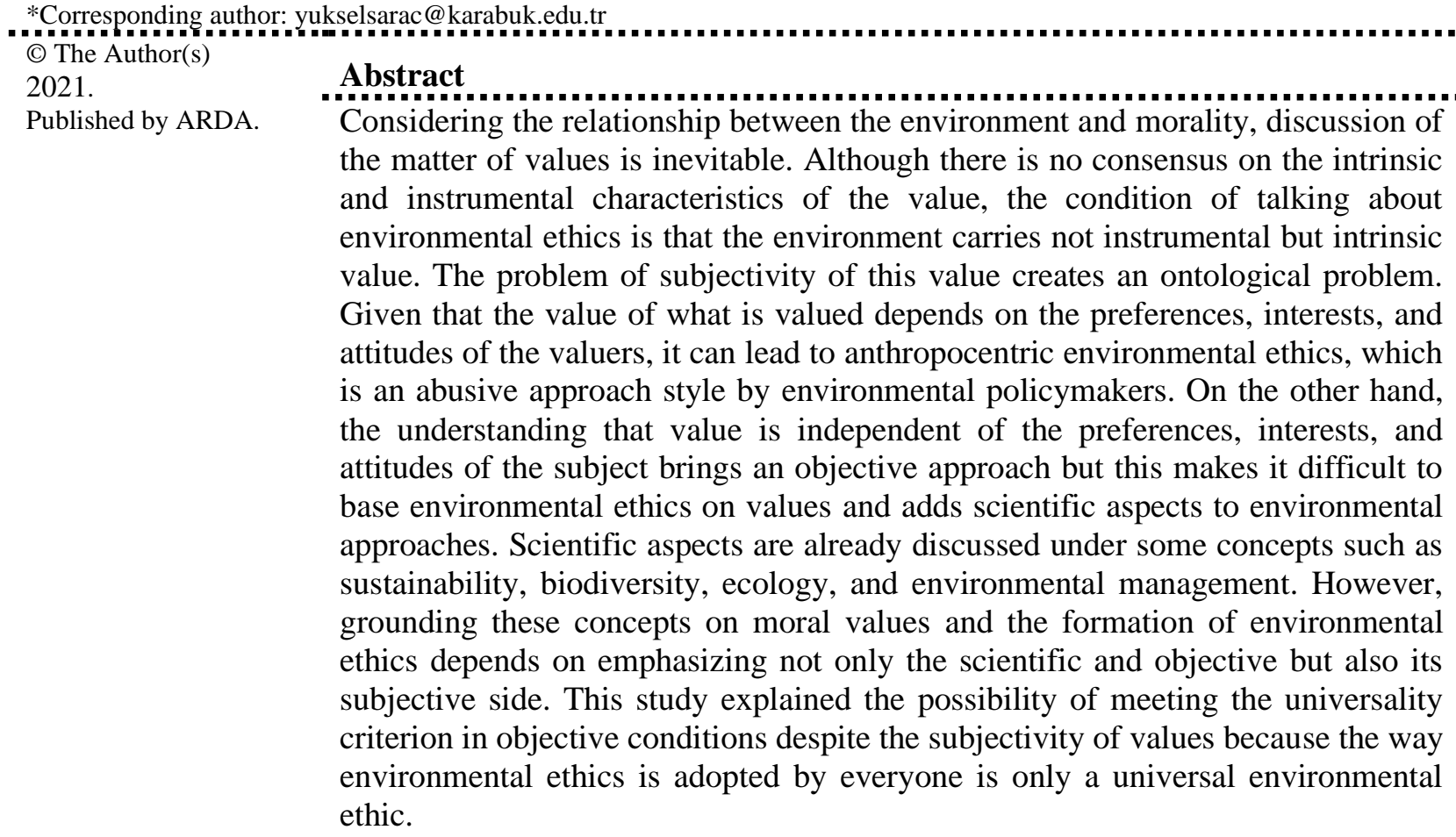

Keywords: : Environment, Value, Intrinsic, Instrumental, Ethics

\section{Introduction}

We logically conclude that universality requires objectivity and that's why the universal environmental ethics should be based on objective value-based moral norms. Objectivity is a necessary condition for the determination of universal principles that may be valid everywhere. However, value, in the most general sense, is the meaning that the aspiring and needing subject attributes to that object as a result of his or her relationship established with the object. By nature and its definition, it does not have the quality of objectivity by many moral philosophers, although those who think the opposite are in the minority. Accordingly, this general definition of value emphasizes the subjective side of the valuers. What we think would be a remedy for the sake of creating a universal environmental ethic is to be able to show that establishing objective moral norms is actually consistent with the subjective aspect of value. Before attempting to demonstrate this consistency, it is essential to clarify whether its value is intrinsic or instrumental among the requirements of talking about an environmental ethic.

To take environmental ethics seriously is to adopt the idea that it is not instrumentally valuable but intrinsically, since the definition of instrumental value usually indicates the use or benefits of environment in terms of human welfare. That is, a thing is instrumentally valuable if it is good for the sake of something else, opens up a room for management ethics. What is the reason of this, in this sense, is that the phrase "for the sake of something

This work is licensed under a Creative Commons Attribution License (https://creativecommons.org/licenses/by/4.0/) that allows others to share and adapt the material for any purpose (even commercially), in any medium with an acknowledgement of the work's authorship and initial publication in this journal. 
else" clearly refers to any usefulness for human purposes. However, the possibility of talking about an environmental ethics requires intrinsically valuation of it in order that it can be "an ethic the beneficiary of which is the environment per se" [1]. John O'Neill, who is an environmental philosopher at Lancaster University, suggests a proponent definition of intrinsic value as "independent of any instrumental usefulness for limited human purposes" and defends that a thing is intrinsically valuable, "if it is an end in itself" [2]. Despite the idea about intrinsic value has been commonly shared by many environmental philosophers, there is no consensus on whether it is objective or subjective. Some environmental philosophers defend value's objectively taking place in nature whereas others take the side of subjective attribution of value to nature. The division between these claims is the main subject of this study. Addressing such a division is of great importance in terms of what the nature of environmental values should be. There are advantages and disadvantages in both claims.

\section{Is there really value in nature or of nature?}

Holmes Rolston III, who is known for his idea of objective value in environment, argues in his essay "Value in Nature and the Nature of Value" that "a sentient valuer is not necessary for value" [3]; if not, we may err in looking for that value in subject's experience. Worse, in addition to this subjectivist fallacy, if we think that valuers are only humans and their valuing completely depends on their choices, attitudes, and preferences, we also fall into the anthropocentric fallacy. Although certain beings are unconscious or insentient beings, they are holders of value even if there is no any beholder. Holding a value is a sufficient condition of its objectiveness. But is Rolston really right? Like J. Baird Callicott, who is known as commentator of Aldo Leopold and as an important environmental philosopher, a subject valuer who can evaluate. The existence of value depends on the existence of subjects' evaluative attitudes. Think about plants which are intrinsically valuable and that value is objective, is there anything which matters to them? Although plants have a good of their own or an end in them, can we talk about a plant value? I guess nobody answers these questions with 'yes'.

Another environmental philosopher, Y. S. Lo also suggests that values stem from the evaluative attitudes of humans. Since only human beings are the source of all values, no subject means no value. Nevertheless, Rolston and the other objectivists claim, by giving a reference to Routley's 'the last man argument', that such an understanding ultimately leads to the conclusion that World without humans has nothing of value since subjectivism entails non-humans are only instrumentally valuable. According to this argument, Routley (later Richard Sylvan) wants us to imagine that all humans are dead except a man. He, the Last Man, gives a decision that if he himself is coming to an end, he must take everything else with them, so the last man can destroy every living animal, plant, bacteria, etc. tries to (he has access to very powerful technology so he can achieve his goals).Would this last man think that if he was already going to die, the unmanned world would not be worth anything, and would he destroy it too, or over and above, would he not think he had value and destroy it? For Routley in his words "What he does is quite permissible according to basic chauvinism, but on environmental grounds what he does is wrong"[4]. What Routley emphasizes by this thought experiment is not to come up with whether the intuition is primary for moral reasoning; rather, he shows the last man's displaying disapproving behavior.

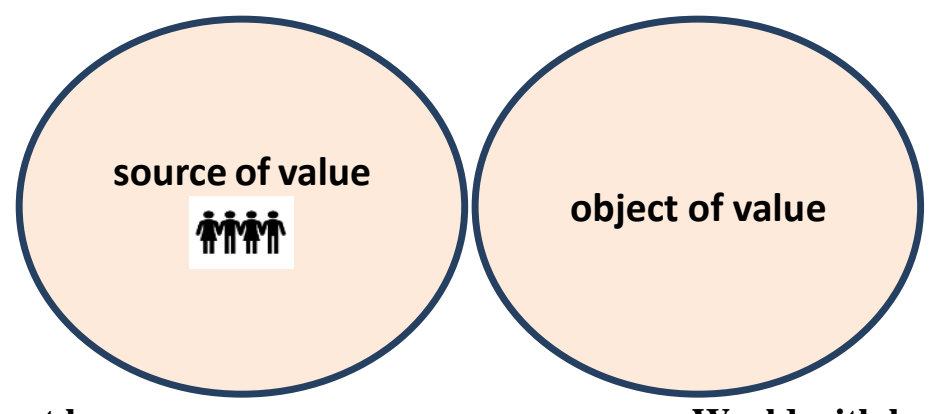

World without humans

World with humans

Figure 1. The distinction between the object and the source of value

According to Rolston, for the subjectivists, then, it would not be wrong for the last man to destroy the world. If only humans have the ability to create values, then World without humans would also be completely valueless or has no actual value. The Last Man has done nothing wrong. So then, can we talk about a value of a world in which nobody exists and know it? In order to eliminate the problem of the universality of subjective value and 
to speak of the value of an unmanned world, Rolston points to the need to extend moral consideration to nonhuman beings, and to a new ethic that nature has a value independent of our interests. This is not the primary aim of this study but I will continue to compare the objectivist account of intrinsic value with the subjectivist one by entering into details as needed. Well, does the last man argument success in defense of an environmental ethic for objectivists? No, rather, it fails due to their erroneous assumption that "subjectivism entails nonhumans have only instrumental value" [2]. Subjectivists point out that this assumption confuses the source and object of value. Namely, nature is the object of intrinsic value whereas human consciousness is the only source of values. That's why, nature is value-laden entity and human being just reveals this value. Callicott does not use the word 'object; rather, it uses the word 'locus' in order to indicate that all natural beings are to be valuable, "not in themselves but for themselves"[5]. This quotation actually briefs the answers of Callicott and those who think like him on such crucial questions objectivists ask as that 'how will objective moral norms be consistent with the subjective aspect of intrinsic value' and that 'doesn't value of this kind lead to the problem of universality of itself?'

To overcome these problems, ideal observer account of subjectivism about intrinsic value has been theorized by Lo who proposes that the universality of subjectivist account of intrinsic value can be revealed by an ideal observer.

\section{Ideal observer account}

The ideal observer solution provides a way of getting rid of moral solipsism and sheds the light of value on that world in which valuers never exist. As we know, moral solipsism is a radical idealism that reduces everything to the subject and accepts those subjects' outside as the subjects' designs. In order to reveal the universal subjective value theory, even if the existence of value depends on the subjects, the value must be independent of the evaluative attitudes of the subjects (remember the distinction between the object of value and the source of value). This account of subjectivism avoids facing such problems by considering that "if what is of value is what ideal observers would value, and if we assume that such ideal valuers would find the flourishing nonhuman earth valuable, then the actual value of the earth is guaranteed even if humans or other real valuers never arrive on the scene" [6]. Thereby, valued object doesn't need to be contemporaneous with the valuer. I will not explain what an ideal observer version of subjectivist value exactly is but just elaborate for the sake of the subject matter of this study.

O'Neill and Lo developed their ideas about intrinsic value by giving some references to Hume. In particular, Lo concealed the problems with subjectivist theory of intrinsic value by extending moral questions about what things are intrinsically valuable to practical questions about dispositions of human beings, habits, and psychological capacities. His metaethical theory of intrinsic value is regarded as ontologically subjectivist since he defends that the existence of value depends upon the existence of subjects' evaluative characteristics. Since we are subjects with tendencies, habits, and psychological capacities, our dispositional characteristics prevent us from establishing a universal value. Nonetheless, it is not impossible to set such a theory anyway if we assume an ideal observer without tendencies, habits, and psychological capacities. Lo generally frames his solution called as the dispositional theory in a way that " $\mathrm{X}$ is (relatively/universally) valuable if and only if (some/all) subjects are disposed, under ideal conditions $\{C\}$, to give certain evaluative responses $\{R\}$ towards $X "$ [7]. These ideal conditions may consist of "being impartial, rational, dispassionate, and well-informed about the thing under evaluation" [7]. Thereby, the frame reduces facts about values to facts about valuers' dispositional attitudes and it is neutral between universalism and relativism. In other words, once evaluating an object intrinsically, if everyone were under ideal conditions, it would be universally valuable; however, people's dispositional attitudes are evolutionary, cultural, and personal products. Therefore, we are unfortunately under less than ideal conditions and lack of reliable moral sentiments. It is possible to create values and make them universal by means of cultivating, negotiating about, and converge in people's evaluative attitudes. In that way, we can reach at a common ground that only under ideal conditions we may have reliable sentiments which are the very decisive of moral norms from Hume's point of view. This conceptual analysis implicitly implies metaethical universalism, the view that morally good or bad things are determined by people's approval or disapproval dispositions under ideal conditions. Likewise, if what is valuable is what ideal observers will value, and assuming that those ideal valuers would value the non-human world, then the value of the world is established before and after people or other valuers arrive at the planet. Think of value of Saturn planet or value of a dead star in another galaxy in which valuers never exist. That is why valued object doesn't need to be contemporaneous with the valuer. 
Well, if we consider the world we live in and us with tendencies, habits, and psychological mechanisms, how or where will the ideal observer be for this world? Lo argues that Humean value is both objective and subjective, i.e., to discover values means to create values. We are only subjects uncovering such values. As an empirical issue, we try to find out or create values to common all. Since our evaluative attitudes are malleable, it can be cultivated. That's why, it is possible to create values and make them universal by developing, negotiating, and converging people's evaluative attitudes. Thus, we can reach a common point where we can only have reliable moral sentiments, which are the determinants of morality from Hume's point of view, only under ideal conditions. To illustrate, from Hume's point of view, justice as an artificial virtue is one of the created values.

\subsection{Justice as a universal value}

Now, it can be questioned why we aim at reaching universality through ideal conditions if ideal conditions are actually objective criteria while adopting subjectivist account. We can cite this as an example of what Hume calls an artificial virtue of justice. Not everyone may have benevolence in sufficient degree to be impartial, which is the reason justice is established. Lo states "if everyone, by nature, had a tender regard for everyone else, and pursued public interest naturally, then there would no longer be any jealousy or conflict of interests among people, which the rules of justice are supposed to resolve [...]" [7]. Not everyone's understanding of justice would be different either. Nevertheless, the self-interested motive in a larger society gives rise society to dissolve without mutual understandings of public interests. That is why pursuing other interests and following the rules of justice becomes important for the members of a society. Hume says that "it will be for my interest to leave another in the possession of his goods, provided he will act in the same manner with regard to me" [8]. It is certain that this is easy task in close relations; however, the more society grows, the more it is difficult to take others' interests into account. In a larger society, Hume introduced a sense of justice and injustice to the maintenance of the convention of it. This sense indicates a natural inclination which gets people "to feel the sentiment of approbation/disapprobation towards the observance/violation of the rules of justice" [7]. Even if the sense of justice and injustice emerges via sympathy which is a natural psychological mechanism, "it is thereafter augmented and secured by the artifice of custom and education" [7].

Hume's sense of sympathy or "human sympathy [which he sees as a psychological mechanism] can thereby be transformed into bioempathy" [7] for the environment and extended to all members of the environmental community, just as it plays a role as a fundamental factor in establishing the virtue of justice. We humans, like all natural beings, are members of the same biotic community. I think that if our evaluative dispositions are cultivable, we can change the attitudes of people towards environment, and thereby constitute a new environmental ethics shared by the public at large. Like the virtue of justice, we can create some environmental virtues such as modesty and thoughtfulness. The sentiment of sympathy which Hume sees as a psychological mechanism may be expanded to all members of the biotic community. Like all natural entities, we human beings are also the members of the same biotic community.

\section{A different approach to the issue from John Rawls}

Like Lo, John Rawls who is the Harward social scientist, born in Baltimore, proposes the theory of justice which is the most upheld and put into practice today. His theory is such a theory that liberals cannot possibly dislike it because it claims that every person can achieve these principles of justice by exercising self-reflection under certain conditions. In other words, it does not derive its strength from religion or human nature; rather, it used social contract rules presented by Locke, Rousseau, Hobbes (even Kant). Rawls wrote the book $A$ Theory of Justice which explains his famous principle of social justice. He presented two principles that must be read in a lexicographical way since the first principle is prior to the second principle. They are:

"First; each person is to have an equal right to the most extensive scheme of equal basic liberties compatible with a similar scheme of liberties for others.

Second; social and economic inequalities are to be arranged so that they are both (a) reasonably expected to be everyone's advantage, and (b) attached to positions and offices open to all" [9].

So where did Rawls derive these two principles from? The main issue for him is to explain how to adopt such principles universally. Rawls offered a theoretical "veil of ignorance" according to which all rational players in the social game put themselves in the original position (i.e. the default position) and think under a veil of ignorance to reach the same conclusion. It means that they don't know anything about themselves, their places 
in society, their genders, their finances, etc. while thinking about justice. Nobody wants to maximize his benefits; everyone wants to maximize the situation of those in the worst situation in society. Denying any private information about the players themselves encourages them to get a general point of view that has a strong similarity with the moral one. "Moral conclusions can be reached without abandoning the prudential reasoning under certain procedural bargaining knowledge constraints." In short, moral intuitions take their place to prudential judgments [9].

\section{Conclusion}

In this study, I did not intend to clarify whether the intuition is primary for moral reasoning or vice versa; rather, I have tried to emphasize the possibility of universal environmental values which should be both intrinsic and subjective by nature for the sake of the environmental ethic in the arguments of Lo and Rawls in particular, and Callicott, Rolston, O'Neill in general. I believe that we can talk about an environmental ethic only if we establish a universal ethical system which needs not to be objective. The locus and the source of value is a very persuasive distinction made by Callicott in terms of its applicability and acceptability in defence of environmental ethics. We can say that to create a value is to discover that value in environment. However, the subjectivity of values does not prevent us from reaching a universal theory of environmental value. My general refences to the theories of Lo and Rawls evinces that both can serve in finding useful hints to establish a universal theory of environmental ethics. Accordingly, we are unaware of others' influences on our psychological capacities, tendencies and of our abilities to control them. If we know our evaluative dispositions, we are aware of the values made by others, and of the different dispositions we shaped. Since our evaluative capacities are malleable, we can change the attitudes of people towards environment, and thereby make a new environmental ethics shared by the public at large.

Like the way Lo identifies ideal conditions in which these tendencies or capacities cannot influence anymore, or the virtue of justice, which Hume called artificial and which Rawls later attains as a result of prudential reasoning substituting later for moral intuitions under the veil of ignorance, we also identify other virtues to get out of this subjectivity and determine universal conditions. That is why both theories can open a door for an objectivist account of intrinsic value through ideal conditions introduced by it. However, this is not entirely an objectivist theory of intrinsic value as Rolston understands. Ideal conditions make intrinsic nature of objects possible to persist in the absence of an observer because value both objective and subjective; to be more implicit, the former depends on the latter. Actually, they are both compatible with and complementary to each other. To find out values means to create values and therefore, observer dependent is equivalent to object dependent. We are only subjects revealing these values. As an empirical matter, we try to discover or create values to common all. Since our evaluative attitudes are malleable, it can be cultivated.

\section{References}

[1] J. B. Callicott, In Defense of The Land Ethic, New York: State University of New York Press, 1989.

[2] J. O'Neill, "The Varieties of Intrinsic Value,” The Monist, vol. 75, p.119-137, 1992.

[3] H. Rolston, "Value in Nature and the Nature of Value," in Conference on Philosophy and the Natural Environment, Royal Institute of Philosophy Supplement: 36, Conference University of Wales, Cardiff, 1993, Cambridge: Cambridge University Press, 1994. pp. 13-30.

[4] R. Routley, "Is There a Need for a New an Environmental Ethic?" in Proceedings of the XVth World Congress of Philosophy, Varna 2010, Varna: Sofia Press, pp. 205

[5] K. Lee, The Source and Locus of Intrinsic Value: A Reexamination, Environmental Ethics, vol. 18, pp.297309, 1996, p. 297

[6] L. Pojman, Paul Pojman, Environmental Ethics: Readings in Theory and Application, Wadsworth Cengage Learning, 2011.

[7] Y. S. Lo, "Making and Finding Values in Nature: From a Humean Point of View," Inquiry: An Interdisciplinary Journal of Philosophy, vol. 49, no. 2, p. 123-147, 2006.

[8] D. Hume, A Treatise of Human Nature, Dover Publications, 2003.

[9] Rawls, J., A theory of Justice, Cambridge: The Belknap Press of Harward University Press, Revised Edition, 1999. 